\title{
A Comparative Study of Blockchain Framework for Waqf Management System
}

\section{Nur Shahellin Mansur Huang and Sharifalillah Nordin}

To Link this Article: http://dx.doi.org/10.6007/IJARBSS/v11-i12/11979

DOI:10.6007/IJARBSS/v11-i12/11979

Received: 11 October 2021, Revised: 16 November 2021, Accepted: 30 November 2021

Published Online: 17 December 2021

In-Text Citation: (Huang \& Nordin, 2021)

To Cite this Article: Huang, N. S. M., \& Nordin, S. (2021). A Comparative Study of Blockchain Framework for Waqf Management System. International Journal of Academic Research in Business and Social Sciences, 11(12), 2482-2491.

\section{Copyright: (c) 2021 The Author(s)}

Published by Human Resource Management Academic Research Society (www.hrmars.com)

This article is published under the Creative Commons Attribution (CC BY 4.0) license. Anyone may reproduce, distribute, translate and create derivative works of this article (for both commercial and non0-commercial purposes), subject to full attribution to the original publication and authors. The full terms of this license may be seen at: http://creativecommons.org/licences/by/4.0/legalcode

\section{Vol. 11, No. 12, 2021, Pg. 2482- 2491}

Full Terms \& Conditions of access and use can be found at http://hrmars.com/index.php/pages/detail/publication-ethics 


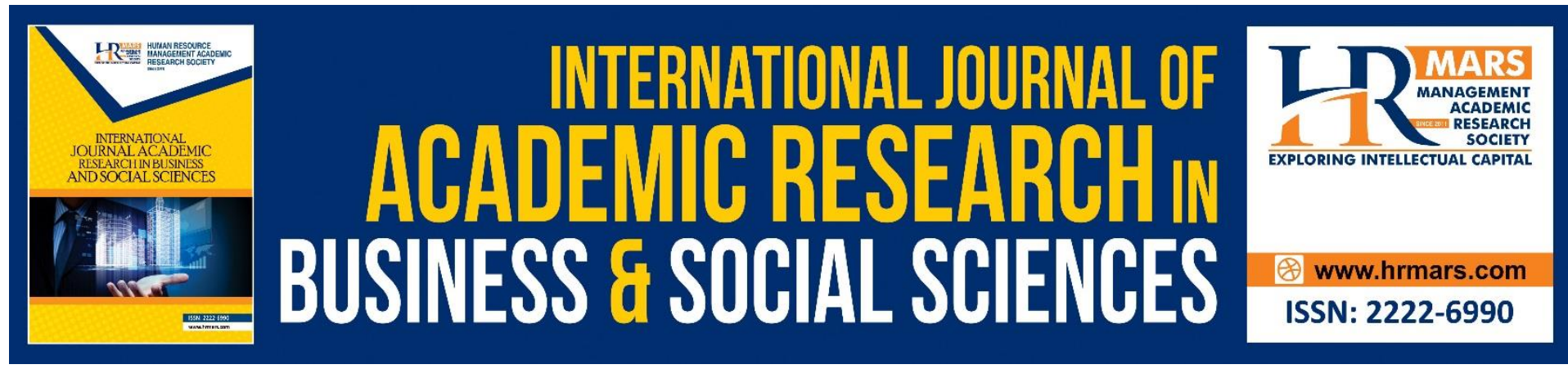

\title{
A Comparative Study of Blockchain Framework for Waqf Management System
}

\author{
Nur Shahellin Mansur Huang and Sharifalillah Nordin \\ Faculty of Computer and Mathematical Sciences Universiti Teknologi MARA (UiTM) Shah \\ Alam, Selangor, Malaysia \\ Email: shahellinnur@yahoo.com, sharifa@tmsk.uitm.edu.my
}

\begin{abstract}
This paper discusses the blockchain frameworks for evaluating trustworthiness in managing waqf management system. The frameworks are Ethereum, Hyperledger, Finterra Waqfchain and Waqf Blockchain (WB). The invention of the blockchain has offered many benefits to the waqf institution since this institution faced many challenges such as lack of data transparency, accountability issues, weak of historical records, improper audit and improper compliance practices that may breaks donors' trust to use waqf system as a platform to make donation. However, the framework has their own pros and cons in order to make waqf management system more transparent, trusted and efficient. As a result, Ethereum framework shows the most suitable blockchain platform that can be used for the waqf management system.

Keywords: Waqf, Blockchain, Waqf blockchain framework, Waqf management system, Ethereum, Hyperledger, Finterra Waqfchain, Waqf Blockchain (WB)
\end{abstract}

\section{Introduction}

Waqf is for mobilizing resources to meet societal needs by contributions of donors (Aziz et al., 2019). An owner donates for waqf and dedicates an inalienable for permanent social benefit, meaning it cannot be sold or disposed of in any other way (Shaikh et al., 2017). Meanwhile, the proceeds are periodically spent that designated by the waqf founder. Besides, cash waqf can be used for building the institutions, for examples, hospitals, schools, and orphanage. Cash waqf usually involve waqf institution, waqif, Investments Corporation, and other institution that have cooperation. According to Mohamed \& Lahsasna (2020), waqf can be in terms of cash benefits that are flexible and liquidity. Sadeq (2002) also stated that waqf referring to cash donations as funds and non-movable assets with continuous income.

However, waqf institutions always faced many challenges in order to manage waqf in proper, effective and efficient ways (Sapuan et al., 2017). Most of waqf's issues are lack of transparency and trust issues due to inefficiencies of managing waqf distribution and misuse of donations happened in waqf management (Shukri et al., 2019). Besides, bottleneck issue also is one of the challenges occurred in traditional waqf's database with high traffic and high dependent on network connectivity. The weak of management system caused waqf fund generated inefficiently and break donors' trust to use waqf system as a platform to make donation (Ahmed et al., 2015). Moreover, the involvement of third parties in waqf system 
makes the transactions subject to high transfer charges (taxes), technical issues, account hacked and transfer limits. Thus, donor will be having a problem to find actual or single platform to track on how their donations are being distributed by waqf institutions and how the funds are being used by charities (Baqutayan, 2018).

According to Azganin (2019), these existing systems are not enough to solve transparency and trust issues. Waqf institutions always faced many problems in order to manage waqf in proper and efficient ways. These existing waqf institutions systems involved third parties for validation process and these involvements-imposed taxes in waqf's transaction. Then it took several days or long period for validation process to review waqf documents and transactions that made in the system (Zulaikha \& Rusmita, 2018). They may use traditional contracts to validate waqf's transaction, manual remittance, physical contracts (sometimes involves wet signature) and lawyers necessary. There are so many waqf assets that people do not know and it is difficult for donors to trace what is going on with all of them. Lack of actual or single platform for donors to see how their donations is being distributed by waqf institutions and check how funds are used by charities (Baqutayan, 2018).

\section{Literature Review}

The invention of the blockchain has offered many benefits to the waqf institutions for better and efficient management in future. The implementation of blockchain in waqf management able to bring a trust and transparency by using distributed ledgers, smart contracts and cryptocurrency. Blockchain is one of the technologies that powers the cryptocurrency where it is open and decentralized ledger that serves as a record of transactions between parties in a manner that is immutable (Ahmad \& Habib, 2019). Blockchain can be used by many applications like banks, insurances, healthcare, automobile and supply chain. It is very useful when dealing with important data like bank records, loans, claims, or any transactions (Mohamed, 2016). Furthermore, organizations of Islamic Cooperation and other Islamic financial institutions are planning to implement and use blockchain since it is gaining attention and give many benefits to their institution (Gazali et al., 2019; Rashid, 2018). In 2018, PwC conducted a survey with 600 executives regarding the involvement of blockchain technology. According to the survey, $82 \%$ of them said that their organization need to have some involvement of blockchain technology (Elasrag \& Hussein, 2019).

The most significant advantages provided by blockchain are the element of trust and transparency (Ahmad \& Habib, 2019). Since the record cannot be changed, it can confirm ownership, provide transparency in transactions and safeguard the sanctity of contracts without the need for a central regulator or certifying authority. Blockchain able to enhance donors' trust to donate where their donations can easily trackable. Waqf with blockchain contribute to the high level of transparency of data especially for the use of waqf's donated funds where donors can see how every of their donations is spent and it able to bring back donors' trust, so, it will encourage donors to donate more (Aziz et al., 2019).

The main characteristics of blockchain are persistency, auditability, anonymity and decentralization. For persistency, the transactions can be validated quickly and cannot be admitted by honest miners for invalid transactions. In blockchain. It is not impossible to rollback or delete the transaction once it is included into blockchain. Next for auditability, data that will be stored in blockchain is based on unspent transaction of user balances. For anonymity, with generated address, user able to interact with other user without reveal their identity (Sultan et al., 2018). For decentralization, data or information that will be stored in blockchain will not keep in a central location or central trusted agency, for example, bank. 
This will eliminate third parties and away from the central location like conventional centralized transaction system that need central authority to validate each transaction that may affect performance bottleneck at servers of the central.

The core blockchain architecture components are node, transaction, block, chain, miners and consensus (Chakraborty et al., 2017). Each block in blockchain its own data and hash value where it contains cryptographic value such as numbers, characters and complex algorithm. Each block also contains a pointer and signature. Pointer is used to point the hash of previous block while signature is used to link all previous block until first block (Allessie et al., 2019; Bassil, 2012). Fig.1 shows architecture blockchain that consists of continuous sequence of blocks (Zheng et al., 2017).

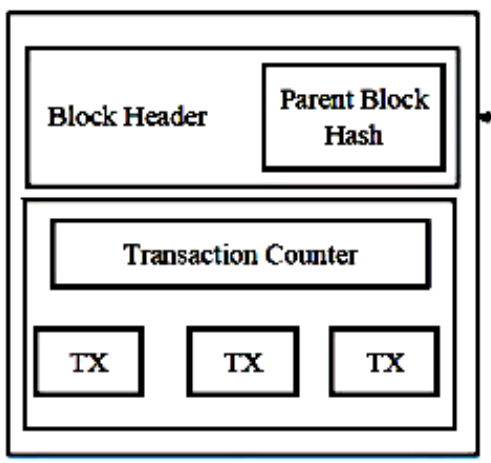

Block i-1

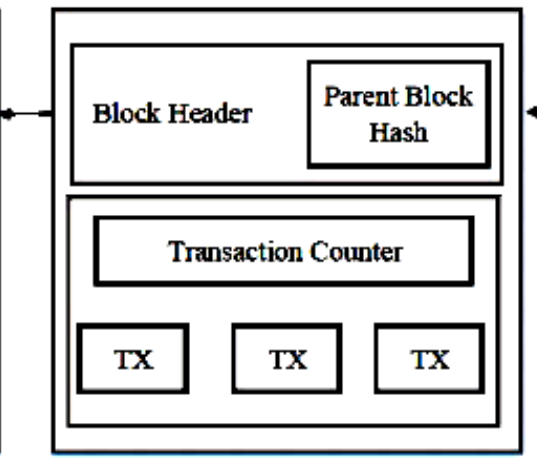

Block i

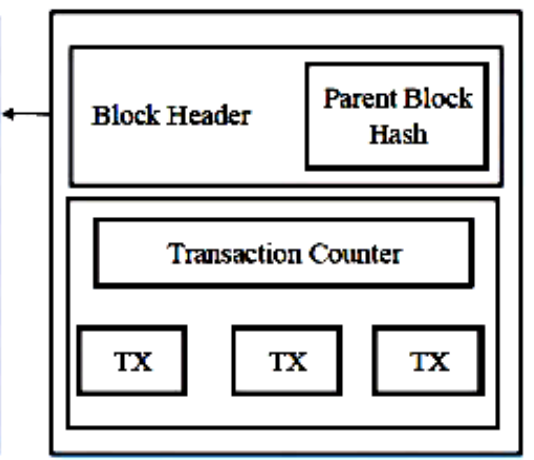

Block i+1

Fig. 1 Architecture of Blockchain

In blockchain technology, the database is known as distributed ledger that is consensually shared and synchronized across multiple waqf's institutions (Zulaikha \& Rusmita, 2018). It includes relevant information such as donor, donation amount, donations received, recipient information, time-stamp, the use of funds through a public profile. Entries in this ledger are permanent, transparent and searchable. With distributed ledgers, it able to ensure the donations are spent correctly and providing a clear view on how charities use and spend the funds received (Ahmad \& Habib, 2019). All data in distributed ledger are interconnected and decentralized. All records in the blockchain cannot be easily erased since blockchain technology provides full transparency of shared ledgers that are immutable. Blockchain technology that use for donations able to make donors to trace on how their donations are being distributed and used by charities to ensure the donations earmarked correctly.

According to Allessie et al (2019), the transactions in blockchain will be verified by using peer-to-peer (P2P) network. Blockchain technology are based on P2P network where there is no need centralize parties to assure the validity of the transactions. Each block in the blockchain will be recorded in P2P network by using assurance and cryptographic mechanism. These consensus mechanisms able to verify the transaction where each user in the network can update and validate the transactions in P2P network. This mechanism also used to build a trust by providing data accuracy and data integrity since it able to record distributed ledger's information in a manner. The idea of blockchain is distributed in P2P network where it permits the non-trusting parties without trusted intermediaries to verify waqf's transaction. Each block in blockchain is P2P network where everyone on the network (blockchain) can interact with each other without the need for a trusted intermediary. 
Blockchain allows the execution of smart contract in P2P network. Smart contract as a system of rule with private regulatory framework that manage the transaction between many parties that involved in the blockchain. It used to verify the information against the entry on the blockchain (Beklemysheva, 2019). Smart contract can be done in few minutes for validation process, automatic remittance, fraction of the cost, virtual presence (digital signature) and lawyers may not be necessary (Ahmad \& Habib, 2019). The regulators will able to keep track all the changes in the agreement that have been made between the contracting parties by using smart contract (Niforos et al., 2017). As for smart contracts, the contract could be executed by miners automatically once the contract has been deployed on the blockchain. It can be executed automatically and independent without the need of human intervention.

Blockchain is built with a range of different cryptographic concepts. There are two ways of cryptography that being used in blockchain. The first way is via algorithms called as cryptographic hash functions where the transactions will be used as input. Then, the input will be run through hashing algorithm in order to get the output. SHA is a family of Secure Hash Algorithms that is not encryption but it is a hash function used for checking the sender authentication and message integrity (Zhai et al., 2019). In cryptographic encryption, RSA (Rivest-Shamir-Adleman) is an algorithm used by modern computers to encrypt and decrypt messages. In short, SHA algorithm used for hashing in the blockchain while RSA-2048 algorithm is a key used to encrypt and decrypt messages in order to provide authentication, data integrity, and non-repudiation (Mohsin \& Muneeza, 2019).

\section{Existing Blockchain Framework}

There are many blockchain frameworks that able to provides solutions to many current problems in waqf management system as it possibly enables transactions which is easily auditable, costless verification, enhance data transparency and trusted waqf platform.

\section{A. Ethereum Framework}

Ethereum framework currently used as blockchain platform since it is a decentralized and distributed platform (Agarwal et al., 2018; Saleh et al., 2019). Smart contract that used in this framework used for writing protocols and rules to control transactions' flow (Agarwal et al., 2018). Ethereum is suitable platform for tracking donations as it able to make charitable organizations increase transparency of data and their accounting of operations donors, and donors able to monitor and track their donation based on blockchain technology (Saleh et al., 2019). One of language that implemented for smart contract in this platform is Solidity and this platform can be developed using Node.js. The process of donations and receiving funds can be developed by using Telegram bots for simulating.

Charity-Chain is one of the systems that used Ethereum framework as a public platform. This system is a decentralised network that helps organisations to run projects transparency. Smart contract that used in this system is accessible to anyone in the network, independently verified and performs process of donation. According to Sirisha et al. (2019), Charity-Chain also consists of Ethereum Virtual Machine (EVM), consensus protocols and Interplanetary File System (IPFS). Funders such as small donors, impact investors, philanthropic organisations and others can monitor the transactions of donors by using this system. User of the system will be able to enhance their trust by tracking and viewing all the information and details of their donations such as the status process of their donations made. 
Charity organizations also able to register through this system and provide details about the donations to attract people to donate with them.

DApp system also used Ethereum framework as a charity fundraiser to verify and demonstrate core functions for charity platform. Solidity is used for smart contact and the system is tested by using MetaMask Browser Extension. The beneficiary will be created unique token request when the donation has been completed in order to test the function of funds transfer. Funds transfer and funds approval will be verified by using DApp system. To increase the transparency of data, all transactions will be recorded on the blockchain and this will increase the trust for every donor in charity organizations (Baokun \& Hee, 2019). Hence, Ethereum framework that used in charity system able to enhance public's trust and motivate donor to contribute more on donations since it provides transparency in every donation.

\section{B. Hyperledger Framework}

Hyperledger is an open source framework that serves various distributed ledger such as Hyperledger Fabric, Indy and Sawtooth for enterprise blockchain deployments. It provides stable framework for private donation system (Jeong et al., 2020) with Hyperledger Ursa as libraries and Hyperledger Caliper as tools. This system protects sponsors' privacy to enhance the transparency of donation. Docker is used for virtualization platform in Hyperledger Fabric blockchain.

The environments to implement this blockchain technology and certificate authority server are NodeJS, Ubuntu, Golang and Docker-Compose. All certificates, blocks and keys are created in this system to complete the creation of channels. The system with Hyperledger framework support flow of funds and accounting of operations donors in order to verify the information and enhance data transparency of the system. In addition, Hyperledger framework also used for government fund tracking system since it provides transparency for all government transactions. The transactions can be verified and cannot be altered so that it will be no discrepancies.

Mohite and Acharya (2018) stated that in government fund tracking system, a prototype that is used is Hyperledger Composer from the Linux Foundation. A modelling language that used in Hyperledger Composer is CTO. Participant, assets and transactions are the resources that used in the system. Hyperledger Composer tool defines a business model and deploy it on Hyperledger fabric. The money that being distributed can be tracked and this give impact on the economic development since it reduces the corruption. Everyone in the network can see how the money being distributed time to time since all transactions are clearly visible and public.

\section{Finterra Waqfchain Framework}

Finterra Waqfchain framework is presented in visual form that can easily shareable on social media platforms. This framework recurring donations continuously and manage onetime that grows with every donation. Finterra as a case and business model generate tokens. The created tokens will be distributed to the funders that are already participated in the system. These tokens represent right into indivisible project that produce benefit. In this framework, waqif able to track the status of their donations and donors will be notified with every update on the fund's trip. The process of tracking, checking and updates will be posted on the tracking page using this platform (Mohamed \& Lahsasna, 2020). 


\section{Waqf Blockchain (WB) Framework}

Waqf Blockchain (WB) framework is one of the frameworks that able to provide facilities in raising cash waqf using blockchain technology. WB employed qualitative research approach to obtain a multifaceted understanding of waqf experts views concerning blockchain in addressing waqf management.

The data collection in WB framework are from views and opinion, semi-structured interviews with two experts who comprised of blockchain and Shariah scholar in waqf. As authorised by the waqf, the beneficiary can collect the tractor from the supplier. Upon payment, the transaction has to be recorded in the system so as to avoid data manipulation. Using WB framework, the transaction could be easily traced as blockchain keeps its records accurately. The technology of blockchain works closely with accuracy and upon detecting any data manipulation. Therefore, this waqf blockchain framework can easily identify any corruption that takes place in the waqf centres (Zulaikha \& Rusmita, 2018).

\section{Results and Discussion}

Table 1 shows the comparison between existing blockchain framework. Based on the table, Ethereum and Hyperledger frameworks are highly flexible frameworks in some aspect rather than Finterra, WaqfChain and WB frameworks. Ethereum framework has powerful smart contracts that makes the platform suitable for all kind of system or application. Meanwhile, Hyperledger framework able to solve performance scalability and handle privacy issues by providing permissioned access control. The most essential different between Ethereum and Hyperledger frameworks are the way and the main purpose they are designed on whereby Ethereum framework are purposely for mass consumption while Hyperledger framework are for business purposes.

TABLE 1: Comparison of Existing Blockchain Framework

\begin{tabular}{|l|l|l|l|l|}
\hline \multirow{2}{*}{ Aspect } & \multicolumn{4}{|c|}{ Blockchain Framework } \\
\cline { 2 - 5 } & Ethereum & \multicolumn{1}{|c|}{ Hyperledger } & \multicolumn{1}{|c|}{$\begin{array}{c}\text { Finterra } \\
\text { Waqfchain }\end{array}$} & \multicolumn{1}{|c|}{$\begin{array}{c}\text { Waqf } \\
\text { Blockchain } \\
\text { (WB) }\end{array}$} \\
\hline Code Type & Open source & Open source & Open source & Open source \\
\hline Language & JavaScript & Python & JavaScript & JavaScript \\
\hline Community & $\begin{array}{l}\text { Regular } \\
\text { updates }\end{array}$ & Regular updates & Not very active & Not very active \\
\hline Ledger Type & $\begin{array}{l}\text { Private and } \\
\text { public }\end{array}$ & Private & Private & Private \\
\hline Smart Contract & Yes & Yes & Yes & No \\
\hline Cryptocurrency & Yes & No & Yes & No \\
\hline
\end{tabular}

Distributed ledgers in Ethereum framework can be either private or public without any permission while Hyperledger, Finterra WaqfChain and WB frameworks are permissioned and private network only. It shows that only Ethereum allows anybody to participate at any time in the network. The other frameworks like Hyperledger, WaqfChain and WB have participants like predefined community that only able to access the network. If anyone wants to access or join the network, they need to request permission. For instance, Hyperledger Fabric provides different user roles for all the nodes in the blockchain. It also provides private channels of conversation between nodes in the blockchain which cannot be read by other 
nodes in the network. So, if the problem needs to solve is in public domain, Ethereum is a best solution. But, if a solution involving private entities with some abstraction required, Hyperledger is a better solution.

Proof-of-Work or PoW is one of the algorithms that used in Ethereum framework. All participated users in the network need to reach consensus either some users in the network need to be involved in some transaction or not. Once all participated users agreed, all of them able to access to all entries created in the ledger. However, no consensus needed in Hyperledger Fabric and it only allows participated user to choose in agreement protocol or known as PBFT. This means that two or more participated users able to agree on a key and get the same output or outcome. It is almost same as Finterra WaqfChain and WB frameworks. It is clear that Hyperledger Fabric able to enhance privacy and performance scalability by restricted access to the transactions and allows fine-grained to control over consensus.

In terms of cryptocurrency, Ethereum and Finterra WaqfChain require cryptocurrencies for transactions since they have token or coin for cryptocurrency. Meanwhile, Hyperledger and WB does not have built-in native cryptocurrency. Since the Ethereum and Finterra WaqfChain have its own token for cryptocurrency, these frameworks give advantageous over Hyperledger and WB since Hyperledger and WB frameworks do not provide cryptocurrency. Even though Finterra WaqfChain and WB frameworks are intended to be implemented in waqf system, these frameworks still not fully suitable to be used in larger organization of waqf management areas since the type of distributed ledger are private and not very active in community to be always updated time to time. Hence, Ethereum shows as an ideal framework for developing the waqf system by using its ledger type, smart contract and cryptocurrency rather than other frameworks. Ethereum is the best blockchain framework since it is public blockchain and users do not require permission to participate in transactions. Ethereum has a native cryptocurrency that able to facilitate transactions alongside smart contracts, enables the deployment of smart contracts and decentralized applications which is DApp to be built and run without any downtime, fraud or interference from third parties.

\section{Conclusion}

Embedding innovative blockchain and waqf will encourage the parties intervene in waqf to trust in waqf chain to raise funds and sustain the development of the Islamic society Blockchain can be advantageous to preserve transactions made by waqifs in a trustworthy manner. Blockchain that keeps each transaction record in a secure manner without any data loss or manipulation. The analysis showed that waqf management system will be more trusted and effective if there is the use of blockchain in the system. Donors able to build their trust on waqf management system if the system provide data transparency and easy trackable for every transaction made. Waqf management system with blockchain technology able to reduce criticism among donors and makes the charity organizations increase the trust and gain revenues from donors' trust. This paper found that Ethereum framework is the best and most suitable blockchain platform that can be used for the waqf management system after analyzed from the comparison between Hyperledger, Finterra WaqfChain and WB frameworks. Therefore, the implementation of Ethereum framework in waqf management system will make the whole process in waqf system more transparency in terms of data and operations in accounting, and it will enable the system to eliminate from third parties between donors and charities. 


\section{Acknowledgements}

The authors would like to thank to the Faculty of Computer and Mathematical Sciences, Universiti Teknologi MARA, Malaysia for the support throughout this research.

\section{References}

Aziz, A. H., Hamid, B. A., \& Bouheraoua, S. (2019). Maximizing social impact through waqf solutions. International Bank for Reconstruction and Development.

Shaikh, S. A., Ismail, A. G., \& Shafiai, M. (2017). Application of waqf for social and development finance. ISRA International Journal of Islamic Finance, 9, 5-14.

Mohamed, G., \& Lahsasna, A. (2020). Blockchain waqf: enabling access to social Islamic finance. EasyChair Preprint 2919.

Sapuan, N. M., Zeni, N. A., \& Hashim, S. L. (2017). Elevation of waqf industry for social wellbeing in Malaysia: issues and challenges. International Journal of Advanced Biotechnology and Research (IJBR), 8, 312-318.

Shukri, N., Zamri, S., Muneeza, A., \& Ghulam, H. (2019). Waqf Development in Marawi City via Issuance of Perpetual Waqf Sukuk. International Journal of Management and Applied Research, 6, 68-80.

Ahmed, U., Mohammed, M. O., \& Ogunbado, A. F. (2015). Examining the Traditional WaqfBased Financing Methods and Their Implications on Socio-Economic Development. IOSR Journal of Business and Management, 17, 119-125.

Baqutayan, S. M. (2018). Waqf revival: A policy perspective. Journal of Science Technology and Innovation Policy, 4, 20-27.

Azganin, H. (2019). Redevelopment of idle waqf property through financial technology: Case of Malaysia. International Review of Entrepreneurial Finance, 2, 42-58.

Zulaikha, S., \& Rusmita, S. A. (2018). Blockchain for waqf management. KnE Social Sciences.

Ahmad, A. U. F., \& Habib, H. (2019). Using blockchain and smart contracts for waqf institutions.

Mohamed, H. (2016). The blockchain and Islamic finance. Journal of Islamic Banking and Finance, 27-30.

Gazali, H. M., \& Che, C. M. H. (2019). A conceptual framework for cash waqf with blockchain in financing education for the Islamic religious school in Malaysia. Al-Itqan: Journal of Islamic Sciences and Comparative Studies, 3, 73-88.

Rashid, S. K. (2018). Potential of waqf in contemporary world. Journal of King Abdul Aziz University: Islamic Economics, 31, 53-69.

Elasrag \& Hussein. (2019). Blockchain for Islamic Finance: Obstacle Challenges. Munich Personal RePEc Archieve (MPRA).

Sultan, K., Ruhi, U., \& Lakhani, R. (2018). Conceptualizing Blockchains: Characteristics \& Applications.

Chakraborty, S., Dutta, K., \& Berndt, D. (2017). Blockchain based resource management.

Allessie, D., Sobolewski, M., \& Vaccari. (2019). Blockchain for digital government. JRC Science for Policy Report.

Bassil, Y. (2012). A simulation model for the waterfall software development life cycle. International Journal of Engineering \& Technology, 2, 2049-3444.

Zheng, Z., Xie, S., Dai, H., Chen, X., \& Wang, H. (2017). An overview of blockchain technology: Architecture, consensus, and future trends. International Congress on Big Data.

Beklemysheva, A. (2019). Making Effective Use of Smart Contracts. 
Niforos, M., Ramachandran, V., \& Rehermann, T. (2017). Block Chain: Opportunities for Private Enterprises in Emerging Market. International Finance Corporation.

Zhai, S. Y., Yuanyuan, L., Jing, Q., Cheng, Z., \& Jiangming. (2019). Research on the Application of Cryptography on the Blockchain. Journal of Physics: Conference Series.

Mohsin, M., \& Muneeza, A. (2019). Integrating waqf crowdfunding into the blockchain: a modern approach for creating a waqf market. Fintech in Islamic Finance Theory and Practice, 266-280.

Agarwal, Pratyush, J., Shruti, M., \& Abhijit. (2018). Decentralized and financial approach to effective charity.

Saleh, H., Avdoshin, S., \& Dzhonov, A. (2019). Platform for tracking donations of charitable foundations based on blockchain technology. Actual Problems of Systems and Software Engineering (APSSE).

Sirisha, N. S., Agarwal, T., Monde, R., Yadav, R., \& Hande, R. (2019). Proposed solution for trackable donations using blockchain. International Conference on Nascent Technologies in Engineering (ICNTE).

Baokun, H., \& He, L. (2019). Research on charity system based on blockchain. IOP Conference Series: Materials Science and Engineering.

Jeong, J., Kim, D., Lee, Y., Jung, J., \& Son, Y. (2020). A study of private donation system based on blockchain for transparency and privacy. International Conference on Electronics, Information, and Communication (ICEIC).

Mohite, A., \& Acharya, A. (2018). Blockchain for government fund tracking using Hyperledger. International Conference on Computational Techniques, Electronics and Mechanical Systems (CTEMS). 